\title{
Urodimento
}

REVISTA DE ESTUDOS EM ARTES CÊNICAS

E-ISSN 2358.6958

\section{Notas sobre o Teatro Musical de Eduardo Dussek}

\author{
Luís Francisco Wasilewski
}

Para citar este artigo:

WASILEWSKI, Luís Francisco. Notas sobre o Teatro Musical de Eduardo Dussek. Urdimento - Revista de Estudos em Artes Cênicas, Florianópolis, v. 2, n. 41, set. 2021.

doi DOI: http:/dx.doi.org/10.5965/1414573102412021e0107

Este artigo passou pelo Plagiarism Detection Software | iThenticate 


\title{
Notas sobre o Teatro Musical de Eduardo Dussek
}

\author{
Luís Francisco Wasilewski ${ }^{1}$
}

\begin{abstract}
Resumo
O artigo estuda duas canções criadas por Eduardo Dussek e Luiz Carlos Góes para - Teatro Musical Brasileiro. São analisadas as canções Alô, Alô, Brasil, composta por Dussek para o show Feiticeira, protagonizado por Marília Pêra, em 1975, e A Loura do Carteado, engendrada por ele em parceria com Góes. Esta foi escrita para a travesti Rogéria cantar em Rio Gay, encenação que estreou no Teatro Alaska, no Rio de Janeiro. A montagem possuía um elenco composto por travestis e sua concepção estética revivia os áureos tempos do Teatro de Revista no Brasil. No artigo também há a descrição do começo da carreira teatral de Dussek, revisitando sua atuação, quando ainda era adolescente, no espetáculo As Desgraças de uma Criança, de Martins Pena, sob direção de Antônio Pedro.
\end{abstract}

Palavras-chave: Eduardo Dussek. Teatro Musical. Teatro de Revista.

\section{Notes about the Musical Theater of Eduardo Dussek}

\begin{abstract}
The article analyses two songs created by Eduardo Dussek and Luiz Carlos Góes for the Brazilian Musical Theater. Here the songs analyzed are Alô, Alô, Brasil, composed by Dussek for the show Feiticeira, casting Marília Pêra, in 1975, and A Loura do Carteado, written by him alongside Góes. This was written for the travesti Rogéria to sing in Rio Gay, acting that starred in Teatro Alaska, Rio de Janeiro. The cast composed by travestis whose aesthetics brought back to life the golden times of Teatro de Revista in Brazil. In the article there is as well the description of the beginning of Dussek's theatrical career, revisiting his acting, when he was still a teenager, in the show As Desgraças de uma Criança, by Martins Pena, directed by Antônio Pedro.
\end{abstract}

Keywords: Eduardo Dussek. Musical Theater. Teatro de Revista in Brazil.

Pós-Doutor em Estudos Culturais pelo Programa Avançado de Cultura Contemporânea(PACC) da UFRJ. Doutor em Literatura Brasileira pela USP (2015). Mestre em Literatura Brasileira pela USP (2009). Possui graduação em Letras Licenciatura Português e Literaturas de Língua Portuguesa pela Universidade Federal do Rio Grande do Sul (2004). fran_theatro@yahoo.com.br

(2) http://lattes.cnpa.br/8940176854947138 (1) https://orcid.org/0000-0001-7620-8295 
Notas acerca del Teatro Musical de Eduardo Dussek

\section{Resumen}

El artículo se estudian dos canciones, creadas por Eduardo Dussek y Luiz Carlos Góes para el Teatro Musical Brasileño. Se analizan las canciones Alô, Alô, Brasil, compuesta por Dussek para el espectáculo Feiticeira, protagonizado por Marília Pêra, en 1975, y A Loura do Carteado, escrita por el mismo Dussek junto a Góes. La última se la escribieron para que la travesti Rogéria la cantara en Rio Gay. Esta actuación que estrenó en el Teatro Alaska, en Rio de Janeiro. Era presentada por un elenco de travestis cuya estética remontaba a los áureos tiempos del Teatro de Revista en Brasil. En el artículo también hay la descripción del empiezo de la carrera teatral de Dussek, mirando hacia su actuación, todavía adolescente, en la escena As Desgraças de uma Criança, de Martins Pena, con la dirección de Antônio Pedro.

Palabras clave: Eduardo Dussek. Teatro Musical. Teatro de Revista en Brasil. 
[...] por um lado, aquela música que ouvíamos - arranjos de valsas, de operetas alemães, de canções de café-concerto, todas novas para mim - era ela própria como um lugar de prazer aéreo, superposto ao outro e mais excitante que ele. Marcel Proust. À sombra das moças em flor

Danço e choro, lembrando noitadas de Santo Daime com Vicente Pereira, Carlos Augusto Strazzer (tantas, tantas perdas), Duse Nacaratti, Patrícia Travassos, Eduardo Dussek, Leiloca. Caio Fernando Abreu. Ney Matogrosso, muito além do bustiê

\section{Introdução}

À memória de Mauro Rasi, Vicente Pereira e Luiz Carlos Góes, por tudo que fizeram.

E para Eduardo Dussek, por tudo que faz.

Este artigo é um dos resultados do projeto de estágio de pós-doutorado intitulado Em busca da genealogia do humor queer na década de 1980, desenvolvido pelo pesquisador, sob supervisão de Heloisa Buarque de Hollanda no PACC (Programa Avançado de Cultura Contemporânea) da UFRJ, entre 2017 e 2019, com apoio financeiro de uma bolsa de pós-doutorado do CNPq. Nele será analisada uma parte da produção de Eduardo Dussek e Luiz Carlos Góes para o Teatro Musical produzido no Brasil. Serão analisadas duas contribuições dos compositores para espetáculos teatrais, a saber, a canção Alô, Alô, Brasil, escrita por Dussek e a parceria da dupla com Vicente Pereira e Jorge Fernando para o show de travestis, Rio Gay, para o qual compuseram A Loura do Carteado. Também é visto o começo da carreira solo de Dussek, atuando como pianista na encenação de As desgraças de uma criança, de Martins Pena.

\section{Surge Dussek e o Besteirol}

O movimento dramatúrgico conhecido com Teatro Besteirol ${ }^{2}$ surgiu na cena

2 O rótulo Besteirol foi dado pelo crítico teatral Macksen Luiz na crítica do espetáculo As 1001 encarnações, de Pompeu Loredo pela Revista Isto é em setembro de 1980. Cf. Brayan, Quem tem um sonho não dança: 
brasileira com a montagem de As mil e uma encarnações de Pompeu Loredo, comédia musical escrita por Mauro Rasi e Vicente Pereira, cujas canções eram assinadas por Eduardo Dussek e Luiz Carlos Góes. Esse quarteto havia engendrado três anos antes outro espetáculo. Faço referência a Cabe Tudo, uma compilação de esquetes ${ }^{3}$ criada por Rasi, Pereira e Góes, a qual seria musicada por Dussek. Por problemas de produção, a montagem que seria assinada por Ary Coslov no final da década de 1970, e teria no elenco nomes como Renata Sorrah, Thais Portinho e Rubens Araújo, acabou não chegando aos palcos.

Foi, aliás, mérito de Rubens a formação da dupla Dussek/Góes. O segundo foi amigo de uma vida inteira do ator e juntos eles mantiveram uma república hippie na Rua Farme de Amoedo, no Rio de Janeiro, que marcou época na cena cultural carioca ${ }^{4}$.

A estreia em cena de Dussek aconteceu em As desgraças de uma criança, de Martins Pena, dirigida por Antônio Pedro em 19735. O músico e ator tinha dezesseis anos quando entrou para o elenco da encenação, no qual também estavam, além de Marco Nanini e Camilla Amado, Marieta Severo, Wolf Maya e Lafayette Galvão. Esse fato transformou Dussek em um talento precoce, tanto sob o prisma cênico

"A melhor definição para a peça pode ser resumida num neologismo carioca, gíria de praia, que significa exatamente aquilo que a palavra resume: Besteirol. Essa divertida bobagem deve conseguir grande sucesso de público".

${ }^{3}$ Patrice Pavis, em seu Dicionário de Teatro, no verbete "esquete" faz uma aproximação deste com o campo da comédia. Eis: "O esquete é uma cena curta que apresenta uma situação geralmente cômica, interpretada por um pequeno número de atores sem caracterização aprofundada ou de intriga aos saltos e insistindo nos momentos engraçados e subversivos. O esquete é, sobretudo, um número de atores de teatro ligeiro que interpretam uma personagem ou uma cena com base em um texto humorístico e satírico, no music hall, no cabaré, na televisão ou no café-teatro. (Pavis, 2008. p. 143)

${ }^{4}$ Antônio Bivar fala da república de Araújo e Góes em seu livro de memórias: Bivar, 1995.

${ }^{5}$ Em sua entrevista para Simon Khoury na Série Bastidores, Camilla Amado, que integrava o elenco de As desgraças de uma criança, fala de como Dussek foi escolhido para o elenco: "Nanini e eu tomávamos muito Mandrix, que eu roubava da gaveta do criado-mudo do papai - ele tomava a droga para dormir - e misturávamos com gim-tônica e ficávamos totalmente grogues, embrulhando as palavras, rindo à toa. Numa noite, já ensaiando a peça, olhamos para uma mesa e vimos um rapaz loiro, com o cabelo esparramado pelo ombro, lindo, batucando na mesa como se estivesse tocando piano. Um piano imaginário. Agora veja que loucura: Nanini e eu nos olhamos e dissemos: 'Eis o nosso pianista'. Me levantei, dirigi-me ao loiro lindo - levei umas três horas para chegar à mesa em que ele estava - e perguntei se ele era pianista. Respondeu que sim. Combinei para ele se apresentar às 15 horas no teatro. O Dussek foi pontual e no que foi tocar para o Neschling, de nervoso errou tudo, e eu e Nanini encantados com ele e não tínhamos a menor dúvida de que ele seria o nosso pianista. O Neschling ponderou: 'Trocar um músico conhecido e respeitado por um sujeito que toca tudo errado e é um ilustre desconhecido?’ O argumento do Nanini e meu foi meio nazista: 'Nós estamos produzindo, queremos o Dussek e fim de papo'. E aí o Dussek se revelou um gênio não só no piano - depois um excelente cantor - mas como um precioso elemento que nos veio do público. Ele criou as maquiagens, foi supercriativo". (Khoury, v. 16. p. 325-327, 2016) 
como também musical.

E há o começo da profícua parceria deste com Wolf Maya no teatro e televisão. Dussek assinou a trilha sonora de Blue Jeans, versão musical do texto dramático Blue Jeans - Uma Peça Sórdida, escrito por Zeno Wilde e Wanderley Bragança. Trata-se do musical mais exitoso da carreira de Maya como encenador, cuja estreia aconteceu em 1991, no Rio de Janeiro. Posteriormente, foi remontado diversas vezes pelo diretor. Outra parceria da dupla Maya/Dussek que merece ser lembrada foi a remontagem de As desgraças de uma criança, de Martins Pena, no Rio de Janeiro, em 1998, onde o primeiro assumiu desta vez a função de encenador e na qual o segundo atuou.

Na televisão o músico compôs Me Segura, especialmente para a personagem Crô, interpretada por Marcelo Serrado na telenovela Fina Estampa, escrita por Aguinaldo Silva, cuja direção era de Maya. E em 2015, o supracitado dirigiu Dussek como ator em / Love Paraisópolis, telenovela escrita por Alcides Nogueira e Mário Teixeira.

\title{
O músico e a exitosa criação de uma música para Marília Pêra
}

Dois anos depois do sucesso de As desgraças de uma criança, o músico tem seu primeiro êxito autoral ao compor para o espetáculo Feiticeira ${ }^{6}$, com Marília Pêra Alô, Alô, Brasil!! Os primeiros versos dela são:

\author{
Alô, alô \\ Quem fala? \\ É do Brasil \\ Alô, alô \\ É da terra do anil \\ Alô, alô \\ Nós vamos apresentar \\ A maior revista, insista em saber \\ Se o nosso show é popular
}

${ }^{6}$ Feiticeira estreou no Rio de Janeiro em 1975. O espetáculo era protagonizado e produzido por Marília Pêra. Era uma coletânea de textos de Clarice Lispector, Jorge Luiz Borges, Carlos Castañeda, Fernando Pessoa, Nelson Motta e outros. Roteiro criado por Fauzi Arap, cuja direção coube a Aderbal Júnior (hoje Aderbal Freire Filho). Sobre o show, ver: Pêra e Souza, 1999, p.115 e 388. 
Alô, Alô, Brasil! é o título de um filme-musical lançado pela Cinédia, em 1935. Entre seus diretores estava João de Barro, o Braguinha, que se notabilizou na cultura brasileira como autor de machinhas carnavalescas. Dussek, durante sua carreira, teve uma parceria com este compositor de clássicos, como Pastorinhas e Yes, nós temos bananas. Um desses momentos foi quando participou ao lado de Miúcha e Braguinha do show Yes, nós temos Braguinha, homenagem ao compositor, encenada no Theatro Municipal do Rio de Janeiro, em 1985.

Sua ligação com a obra de Braguinha vira Teatro Musical quando Dussek se torna um dos intérpretes do espetáculo Sassaricando - e o Rio inventou a marchinha, que estreou no Rio de Janeiro, em 2007, e virou um dos espetáculos brasileiros de carreira mais longeva da história do nosso teatro, ficando em cartaz até 2016. Com roteiro de Rosa Araújo e Sérgio Cabral e direção de Claudio Botelho e Charles Möeller. Braguinha era um dos autores das marchinhas interpretadas em cena, assim como Ary Barroso, Lamartine Babo, Max Nunes e tantos outros. No Livro Os Reis dos Musicais, de Tania Carvalho a dupla de encenadores rememora suas funções na montagem:

Na verdade, Sassaricando é um espetáculo do Claudio. Ele veio para o Rio dirigir Sassaricando e eu fiquei em São Paulo segurando o rojão de Sweet Charity. Acabou virando espetáculo nosso, é como se fosse, mas quem dirigiu mesmo foi o Claudio. Eu fiquei concentrado somente no cenário. [...]. Tive também liberdade para mexer um pouco nos arranjos que vinham no CD já gravado pelo elenco, então pedi ao arranjador Luis Felipe de Lima, meu amigo há 20 anos, filho do Luiz de Lima, que alterasse alguns ritmos, ralentasse algumas coisas, porque eu mesmo não ia aguentar duas horas de marchinhas. Havia um monstro em cena que é o Eduardo Dussek, um ator que muda tudo sempre, mas nesse caso fazia parte do show [...]. Para nós, que sempre carregamos a fama de americanizados, Sassaricando foi muito bom. Provamos que o teatro musical bom não tem nacionalidade e que podemos tratar o teatro não como um produto a ser defendido por leis xenófobas, mas sim como algo moderno e atual, capaz de agradar a tantos quantos estejam interessados em assistir um bom espetáculo (Carvalho, 2009, p.138).

A fala de Botelho sobre a atuação dussekiana no espetáculo levanta um aspecto importante na criação teatral e musical dele, a saber, o caráter da improvisação. Os espectadores que assistiram seus shows podem testemunhar 
que entremeados às suas músicas há comentários satíricos e piadas sobre a realidade brasileira. Algo que o aproxima da figura do compère do Teatro de Revista.

Na primeira edição de seu O Teatro de Revista: Dramaturgia e Convenções, Neyde Veneziano conceitua o Compère:

Aglutinador, apresentador, comentarista, dançarino, cantor, bufão, contador de piadas, ele atravessa a revista de ponta a ponta como a costurar os diversos quadros, cristalizando a dinâmica do pacto com a plateia, característica própria do teatro popular. Este papel era geralmente reservado ao primeiro cômico da companhia, que o deveria desempenhar com brilho, desenvoltura e, principalmente com muita descontração, pois muitas vezes se fazia necessário o improviso com relação ao comportamento do público (Veneziano, 1991l, p.117).

A canção Alô, Alô, Brasil! faz referência em sua letra no gênero Teatro de Revista. A letra original fala em "Nós vamos apresentar a maior revista, insista em saber se o nosso show é popular". Em seu livro Não adianta chorar: Teatro de Revista Brasileiro... Oba!, Neyde Veneziano apresenta um conceito do gênero:

Espetáculo ligeiro, misto de prosa e verso, música e dança, faz, por meio de inúmeros quadros, uma resenha, passando em revista fatos sempre inspirados na atualidade, utilizando jocosas caricaturas, com o objetivo de fornecer ao público uma alegre diversão [...]. Cada um dos seus atos deve terminar numa apoteose (grand final) e o intervalo precisa ser curto para não atrapalhar o ritmo (Veneziano, 1996, p.28).

A ensaísta faz referência ao aspecto apoteótico de cada ato de uma Revista. Uma das características do gênero que se faz presente no final da letra da canção Alô, Alô Brasil! é o Oba! dito por Dussek na música e que fazia parte do coro de encerramento de um espetáculo revisteiro.

Desde sua gênese, em 1975, a canção apareceu em diversos espetáculos musicais, bem como em telenovelas. Montagens como Rio Gay, de Vicente Pereira e dirigida por Jorge Fernando, Mulheres do Pau Brasil, de Zé Adão Barbosa, As Mimosas da Praça Tiradentes, de Gustavo Gasparani e Eduardo Rieche, Raia 30, de 
Miguel Falabella, cuja encenação foi assinada por José Possi Neto, bem como Vamp, o musical de Antônio Calmon e dirigida por Jorge Fernando, tinham Alô, Alô, Brasil! em sua trilha sonora. Da mesma forma, a transformista Laura de Vison7 em seu show que marcou época, no Cabaré Boêmio da Lapa, nas décadas de 1980 e 1990, dublava a canção dussekiana na voz de Pêra. Assim como as telenovelas Rainha da Sucata, de Sílvio de Abreu e Alcides Nogueira, e As filhas da mãe, de Sílvio de Abreu, Alcides Nogueira e Bosco Brasil, tiveram em algum momento a participação da música em sua abertura ou trilha sonora. Convém lembrar que as telenovelas supracitadas e alguns dos espetáculos arrolados, foram dirigidos por Jorge Fernando, outro diretor teatral e televisivo a manter uma longeva parceria com o compositor. Nos últimos shows de Dussek, inclusive no único DVD no qual o intérprete registrou sua trajetória musical, intitulado Dussek é Show, o artista começava suas apresentações cantando Alô, Alô, Brasil.

\section{Dussek: Teatralidade e Paródia}

Em seu livro Quem tem medo de besteirol? a história de um movimento teatral carioca, Flávio Marinho ressalta a teatralidade no repertório dussekiano:

O delicioso das músicas de Dussek desta fase, com ou sem a parceria de Góes é que, mesmo que elas não tenham sido compostas para uma peça, elas contam uma história, têm uma personagem. E a teatralidade destas personagens e histórias vem imbuída de um espírito besteirológico avant la lettre, impressionante seu pioneirismo. Dussek manteve-se fiel ao estilo e, no século XXI, ainda podia ser visto no Café-Teatro Arena (Rio) desafiando, à sua maneira muito pessoal e especial, o repertório de Carmem Miranda. Entre uma música e outra, inventou uma personagem - ele próprio - que, desafiando noções básicas de tempo e espaço, diziase ser amigo íntimo de Carmem Miranda e contava histórias absurdas que teria vivido com ela. Dizia horrores de Carmem, sua homenageada. Dizia horrores de si próprio. Não sobrava ninguém. Só o público rolava de rir. Besteirol puro (Marinho, 2004, p.35).

Marinho cita em seu estudo a letra da canção Chocante como exemplo de

${ }^{7}$ Laura de Vison era o nome artístico do transformista e professor de História Norberto Chucri David (19392007). Seus shows foram marcantes nas décadas de 1980 e 1990, principalmente por causa das performances escatológicas. Em cena Laura comia um fígado de boi cru. Mais sobre os shows da artista, ver: Rodrigues, 2015. 
uma música dos compositores Dussek e Góes que, mesmo não tendo sido escrita para um espetáculo teatral, cria uma narrativa com tensão dramática. Em Chocante acompanhamos um tango-polca, no qual o ouvinte acompanha toda desdita de uma mulher esperando um homem num bar. Outro aspecto ressaltado pelo ensaísta é a teatralidade dos shows do cantor. Já fiz no artigo uma aproximação dos espetáculos do artista com a figura do compère do Teatro de Revista. Uma das primeiras aparições dele na Rede Globo foi em 1980, cantando sua música Nostradamus. Como indumentária utilizava fraque e cueca.

Quando Marinho analisa Quem tem medo de Itália Fausta?, texto dramático de Miguel Magno e Ricardo de Almeida, também considerado como um dos primeiros espetáculos do gênero Besteirol, o ensaísta traça um paralelismo entre a encenação e as canções de Dussek:

Na realidade, Quem tem medo de Itália Fausta? fazia com os gêneros teatrais o mesmo que Eduardo Dussek fazia com a música. Ou seja, enquanto este se apropriava de gêneros musicais específicos, como o fox-canção, o samba-choro ou o tango-polca, para recriá-los de forma muito pessoal, especial e bem-humorada, Magno e Almeida partiam de estereótipos do vaudeville, do drama de costumes ou fantasia psicológica a fim de jogar uma luz sempre irreverente e de fina ironia sobre as tradicionais formas de representação e de literatura dramática (Marinho, 2004, p.36).

O excerto aborda um dos aspectos na encenação de Quem tem medo de Itália Fausta?, a saber, o recurso parodístico na escritura e na representação. Esquetes como Mary I, a Rainha Boba e Helena Fechou a Porta partiam de paródias das interpretações de atrizes importantes do teatro brasileiro. Faço referência a Henriette Morineau, Cacilda Becker e Cleyde Yáconis.

Vejamos a definição do conceito por Linda Hutcheon em Uma teoria da paródia (1985, p.478-48):

A maioria dos teóricos da paródia remontam a raiz etimológica do termo ao substantivo grego parodia, que quer dizer 'contra-canto', e ficam-se por aí. Se olharmos mais atentamente para essa raiz obteremos, no entanto, mais informação. A natureza textual ou discursiva da paródia (por oposição à sátira) é evidente no elemento odos da palavra, que significa canto. O prefixo para tem dois significados, sendo geralmente mencionado apenas um deles - o de 'contra' ou 'oposição'. Desta forma, 


\begin{abstract}
a paródia torna-se uma oposição ou contraste entre textos. Este é, presumivelmente, o ponto de partida formal para a componente de ridículo pragmática habitual da definição: um texto é confrontado com outro, com a intenção de zombar dele ou de o tornar caricato [...].

No entanto, para em grego também pode significar 'ao longo de' e, portanto, existe uma sugestão de um acordo de intimidade, em vez de contraste.
\end{abstract}

A partir do estudo do prefixo para, cujo sentido pode ser o de oposição, porém também algo que está ao lado, Hutcheon demonstra que a paródia pode ser respeitosa ao texto de origem.

Subversão paródica criada por Eduardo Dussek e Luiz Carlos Góes que marcou época na década de 1980 é $A$ índia e o traficante. Releitura feita pela dupla de Índia, de Cascatinha e Inhana, guarânia que foi imortalizada na voz de Gal Costa. Os primeiros versos de $A$ índia e o traficante dizem:

\author{
Noite malandra \\ um luar de espelho \\ no meio da Terra \\ a índia colhe o brilho
}

"Brilho" é uma gíria oitentista com significado de cocaína. E o espelho era um dos locais onde os usuários da substância a aspiravam. Seguindo algo que era praxe nas composições da dupla, a canção tem um aspecto narrativo, no qual vamos acompanhando o turbulento relacionamento amoroso de uma indígena com um traficante. Este acaba levando sua companheira a ser cúmplice em seus crimes e no término da canção, tal qual uma heroína folhetinesca, a índia acaba sendo assassinada no Paraguai.

Hoje, com os movimentos identitários e com a pressão do politicamente correto, a música de Dussek/Góes facilmente entraria para o índex do cancelamento de obras artísticas pelo retrato que faz da figura da indígena a associando com substâncias ilícitas. Quando Sylvio Back dirigiu o documentário Yndio do Brasil em 1995, colocou entre as representações deletérias do índio A índia e o traficante.

Todavia, anos antes, em 1987, a canção, e toda sua comicidade desabrida, fez 
parte do repertório do show Uma Noite com Stella Miranda e Miguel Falabella que estreou na Boate People, no Rio de Janeiro, com roteiro e direção assinados por Flávio Marinho. A cena carioca já vivia sob o apogeu do Teatro Besteirol e da formação de duplas de atores em cena, uma das características dos espetáculos daquele gênero teatral que estava sendo formado. Falabella já havia atuado no exitoso Miguel Falabella e Guilherme Karam: Finalmente Juntos em Finalmente ao Vivo e Miranda vinha de uma sequência de parcerias cênicas com Tim Rescala. Além de ter sido uma das atrizes cantantes a participar de Bar, Doce Bar, encenação que lançou a dupla besteirolista Felipe Pinheiro e Pedro Cardoso.

\section{A criação de uma canção para Rogéria}

Contribuição menos conhecida da dupla Dussek/Góes é A loura do carteado. Em entrevista concedida a mim por Dussek ${ }^{8}$, disse que a música foi criada para o espetáculo Rio Gay, que estreou em 1983, no Teatro Alaska, no Rio de Janeiro. Era a época nas quais travestis históricas, como Rogéria, tentavam reviver, com suas encenações naquela casa de espetáculos, o tempo glorioso do Teatro de Revista. Depois que o gênero começou a viver seu declínio na década de sessenta, foram as travestis que começaram a dar uma sobrevida a ele. O show Les Girls foi modelar nesse sentido. No artigo Sobre o talento de ser fabulosa: os shows de travesti e a invenção da travesti profissional, Thaigo Barcelos Soliva comenta o êxito da encenação:

A estreia de Les Girlsfoi um sucesso nacional, mesmo em um contexto de ditadura, no qual a indústria de entretenimento brasileira passou a ser objeto de censura e controle. Já na abertura do espetáculo, o elenco vestia négligée e espartilho, em uma alusão direta aos shows do teatro de revista no estilo burlesco. Tratava-se de uma comédia musical no melhor estilo, que misturava a estética da Broadway com o teatro de revista brasileiro. Eram onze travestis que acorriam a um médico para resolver seus "problemas de cabeça". Cada uma delas era responsável por um esquete. Cabia ao doutor solucionar o "problema" das moças. Ao fim do show, a famosa canção, que tanto marcou a vida de toda essa geração, era entoada em coro (Soliva, 2018).

${ }^{8}$ Entrevista que realizei com o artista para minha dissertação de mestrado. Wasilewski, 2009. 
Seguindo uma tradição do Teatro de Revista, um importante compositor criou músicas para Les Girts. E uma delas se tornou célebre para o carnaval brasileiro. Faço referência à Mulata Bossa Nova, de João Roberto Kelly que era cantada por Divina Valéria no show. Rogéria conhecia Kelly do tempo em que atuou como maquiadora na TV Rio e o convidou para criar as canções do espetáculo. E chamou Meira Guimarães, importante autor do Teatro de Revista, para assinar o roteiro de Les Girls.

Na segunda edição de O Teatro de Revista no Brasil: Dramaturgia e Convenções, Neyde Veneziano escreve sobre o sucesso das travestis no espetáculo:

Pegando para si o papel sensual da mulher no Teatro de Revista, o grupo de travestis estreou em grande estilo na Boate Stop da Galeria Alaska (Copacabana, Rio de Janeiro), atraindo, estranhamente, o público conservador da classe alta e recebendo amplo apoio da imprensa (Veneziano, 2013, p.117).

Quando a ensaísta fala que Les Girls atraía até um público conservador, é importante lembrar que por muitos anos Rogéria fez questão de usar o epíteto de "Travesti da família brasileira", expressão que tomou de empréstimo da vedete Mary Lincoln, cujo sucesso no Teatro de Revista se deu nas décadas de 1940 e 1950. Lincoln chegou a ser definida como "estrela das famílias brasileiras" (Veneziano, 2010, p.84).

No ano anterior a Rio Gay, Rogéria, Eloína9, Marlene Casanova e Jane di Castro estavam no elenco de Gay Fantasy, de Arnaud Rodrigues com direção de Bibi Ferreira e concepção visual assinada por Joãozinho Trinta.

A ficha técnica de Rio Gay tinha roteiro escrito por Vicente Pereira e direção a cargo de Jorge Fernando, dupla onipresente na trajetória artística do músico. Como já citei anteriormente, Alô, Alô Brasil estava entre as músicas cantadas pelas travestis do elenco da montagem ${ }^{10}$.

Em seu livro Teatro é o melhor programa - um painel da cena carioca de 1973

\footnotetext{
${ }^{9}$ A travesti Eloína adotou este nome em homenagem a grande vedete do Teatro de Revista Eloína Ferraz.

${ }^{10}$ A maioria dos shows do Teatro Alaska na década de 1980 apresentavam travestis cantando e não dublando, como era comum nos shows de boate.
} 
a 2014, Flávio Marinho descreveu o espetáculo:

\begin{abstract}
Aproveitando-se da estrutura do teatro de revista - sketches humorísticos que se alternam com números musicais - Rio Gay procurava se livrar de alguns cacoetes do show de travesti - como as dublagens - e explorava mais a porção ator-cantor de cada artista transformista [...] o diretor geral, Jorge Fernando, situa Rio Gay na sua trajetória: "todos os meus últimos trabalhos, As mil e uma encarnações de Pompeu Loredo, A Receita do Sucesso e Sempre, Sempre Mais (show de Lucinha Lins), foram coisas de cenas picadas, de ritmo, de variedades. Isso faz parte de uma proposta de trabalho que eu já venho realizando há algum tempo. E, de repente, fazer o Rio Gay, com a Rogéria, a Samantha, a Kiriaki, a Casanova, a Desirée e a Elaine, está sendo demais, porque elas são a verdadeira revista". Na ficha técnica, Jorge Fernando dividia os créditos de texto com Vicente Pereira, os de cenário com Américo Issa e ainda assinava a iluminação; figurinos e coreografia de Juan Carlos Berardi; música de Paulo Machado e Vicente Pereira; direção de produção de João Paulo Pinheiro; administração de João Batista Pinheiro e divulgação de Andréa Barreto. No elenco elas eram Rogéria, Marlene Cassanova, Kiriaki, Elaine e Desirée e eles eram Alexandre Mendonça, Fernando Pires, Luís Carlos Machado e Marcos Pimenta. O espetáculo tinha lances muito divertidos e sua principal razão de ser na carismática e talentosa presença de Rogéria. A crítica apreciou o esforço de produção e o público lotou as dependências do Alaska (Marinho, 2016, p.296-297).
\end{abstract}

Quando Rogéria começou seu processo de transição de maquiador das estrelas do teatro e televisão para se tornar vedete11 optou pelo cabelo loiro, inspirado por atrizes de Hollywood como Marlyn Monroe. Dussek e Goés, ao criarem A loura do carteado para que ela cantasse, falam tanto do seu tom de cabelo como também de práticas comuns de várias atrizes do Teatro de Revista, a saber, o hábito de jogar. Vedetes como Angelita Martinez passaram boa parte da sua vida se dividindo entre os palcos, onde desciam enormes escadarias, e mesas de jogo. Um bom exemplo de relato de atrizes daquele período que tinham por hábito o jogo, aparece no livro Dercy de Cabo a Rabo, escrito por Maria Adelaide Amaral (1994). Nele a atriz e vedete Dercy Gonçalves conta suas peripécias nas várias mesas de jogo das quais fez parte.

Eis um excerto da canção A loura do carteado:

${ }^{11}$ Rogéria disse em várias entrevistas que seu nome artístico foi criação da atriz Zélia Hoffman (1924-2007), uma das quais foi maquiadora. 


\author{
Abre-se a porta do saloon \\ No ar existe um certo "Uh" \\ Ela entra violenta e aguenta \\ Qualquer olhar e logo se ambienta \\ Olha com desdém mas todos the gritam \\ "Vem!" \\ Ela sorri com ironia \\ Pois sabe que só ela escolheria \\ A mesa em que iria se sentar \\ Pra jogar, pra ganhar, pra gargalhar \\ Ao ver um homem se arruinar \\ No carteado ela era loura \\ Suas mãos cortavam igual \\ A uma tesoura
}

A letra dá para sua intérprete um caráter heroico, ao mostrar a entrada em um saloon de uma figura que é ao mesmo tempo admirada e destemida. Há a valorização da personagem feminina na música, o que nos dias de hoje é chamado de "empoderamento da travesti ou da mulher".

Também exalta a habilidade feminina no jogo de carteado, bem como a representação da loira que, por muito tempo, foi estigmatizada em nossa cultura, especialmente em programas humorísticos e piadas, com a associação do seu tom de cabelo à burrice. A canção ressalta a habilidade de jogadora da personagem e o fato de que muitos homens vão à ruína financeira em uma jogatina com ela. Algo que também fez parte da vida de algumas vedetes do Teatro de Revista. Ao mesmo tempo que elas faturavam com o financiamento de amantes ricos, o vício em jogo as fez perder uma boa parte do seu patrimônio monetário.

Revisitar a obra dussekiana, seja a sua produção solo como a escrita em parceria com Luiz Carlos Góes é importante, pois são escassos os estudos acadêmicos a fazerem uma análise de sua importância histórica. Os dois possuem uma contribuição rica ao Teatro Musical feito no Brasil. O artigo escolheu duas criações deles para encenações emblemáticas de nossa cena. Todavia, a produção contínua da dupla é maior e merece um grande estudo, visto as limitações de espaço de um artigo acadêmico. 


\section{Referências}

AMARAL, Maria Adelaide. Dercy de cabo a rabo. São Paulo: Globo, 1994.

BIVAR, Antônio. Longe daqui aqui mesmo. São Paulo: Best Seller, 1995.

BRAYAN, Guilherme. Quem tem um sonho não dança: cultura jovem brasileira nos anos 80. Rio de Janeiro/São Paulo: Record, 2004.

CARVALHO, Tania. Charles Möeller e Claudio Botelho: os reis dos musicais. São Paulo: Imprensa Oficial do Estado de São Paulo, 2009.

HUTCHEON, Linda. Uma teoria da paródia: ensinamentos das formas de arte do século XX. Trad. de Teresa Louro Pérez. Lisboa: Edições 70, 1985.

KHOURY, Simon. Bastidores. Rio de Janeiro: Ed. do autor, 2016, v. 16.

MARINHO; Flávio. Quem tem medo de Besteirol? A história de um movimento teatral carioca. Rio de Janeiro: Relume Dumará, 2004.

MARINHO, Flávio. Teatro é o melhor programa - um painel da cena carioca de 1973 a 2014. São Paulo: Giostri, 2016.

PAVIS, Patrice. Dicionário de Teatro. Trad. de J. Guinsburg e Maria Lúcia Pereira. 3a. ed. São Paulo: Perspectiva, 2008.

PÊRA, Marília; SOUZA, Flávio de. Vissi d'arte: 50 anos vividos para a arte. São Paulo: Escrituras, 1999.

RODRIGUES, Walace. Laura de Vison: um(a) artista de nossos tempos de discussão sobre gênero. Revista História e Diversidade, Cárceres, v. 7, n. 2, p.102-116, 2015.

SOLIVA, Thiago Barcelos. Sobre o talento de ser fabulosa: os "shows de travesti" e a invenção da "travesti profissional". Caderno Pagu, Campinas, n. 53, 2018.

VENEZIANO, Neyde. O Teatro de Revista no Brasil: Dramaturgia e Convenções. Campinas: Ed. da Unicamp, 1991.

VENEZIANO, Neyde. Não adianta chorar: Teatro de Revista Brasileiro... Oba!. Campinas: Ed. da Unicamp, 1996.

VENEZIANO, Neyde. As Grandes Vedetes do Brasil. São Paulo: Imprensa Oficial do Estado de São Paulo, 2010.

VENEZIANO, Neyde. O Teatro de Revista no Brasil: Dramaturgia e Convenções. São Paulo: SESI, 2013. 
WASILEWSKI, Luís Francisco. Isto é Besteirol: A obra dramatúrgica de Vicente Pereira no âmbito do Teatro Besteirol. 2009. Dissertação (Mestrado em Literatura Brasileira) - Faculdade de Filosofia, Letras e Ciências Humanas - Universidade de São Paulo, São Paulo, 2009.

Recebido em: 11/06/2021

Aprovado em: 12/08/2021 